\title{
Cytopathological study of salivary gland lesions in rural population: Use of the Milan system for reporting
}

\author{
Mahammadtalha B. ${ }^{1}$, Swami S.Y. ${ }^{2}$ \\ ${ }^{1}$ Dr. Bagwan Mahammadtalha, Post Graduate Student, ${ }^{2}$ Dr. Sunil Y. Swami; Associate Professor, both autours are \\ affiliated with Department of Pathology, S.R.T.R. Government Medical College, Ambajogai, Maharastra, India.
}

Corresponding Author: Dr. Sunil Y. Swami, Bhagwanbaba Chowk, Gitta-Road, Shepwadi, Taluka: Ambajogai, District- Beed, Maharastra, India. E-mail: drsys02@gmail.com

\begin{abstract}
Introduction: Salivary gland lesions are superficial lesions \& seek attention of patient easily. These lesions vary from non-neoplastic to neoplastic ones and from benign to malignant. Impact of changing habits of people may be reflected in spectrum of oral health \& lesions of salivary glands. Objectives and Method: Present study includes the spectrum of distribution of various lesions of salivary glands in the patients visiting tertiary care rural hospital. In the present study, the Milan system was used for reporting salivary gland cytopathology in 150 cases. Results: FNAC proved to be a safe and effective modality in diagnosis and planning management of patients with salivary gland lesionsin the rural based population. Conclusion: Milan system was found characteristically significant for cytopathological diagnosis of SGLs.
\end{abstract}

Key words: Milan system, Cytopathology, Salivary gland, Rural population

\section{Introduction}

Salivary gland diseases usually present as a swelling of the affected gland. FNAC (Fine needle aspiration cytology) is being increasingly used in the diagnosis of the salivary gland swellings [1]. Salivary gland lesions comprise $2-6.5 \%$ of all head and neck neoplasms in adults.

The common presentation is an enlarged mass which is usually accessible for FNAC. Salivary gland tumors are not common; moreover, the associated histopathology of these tumors is extremely varied and complex due to the presence of epithelial and non-epithelial neoplasms, lymphomas, metastatic tumors and non-neoplastic lesions in the salivary glands [2].

The rapidity for diagnosis, low morbidity and a high diagnostic accuracy makes FNAC a popular method for evaluating the salivary gland neoplasms before any surgical intervention [3].

\section{Material and Methods}

This study included 150patients presented with salivary gland swellings.

Type of study: Prospective and observational study. Inclusion criteria: All cases of salivary gland lesions were included in the present study.

Exclusion criteria: Patients on conservative treatment and those referred to other hospitals were excluded from the study.

Detail clinical history was taken, and local examination followed by systemic examination was done in all patients. After taking consent, FNAC was done using 21-23-gauge needle attached to a $10 \mathrm{ml}$ syringe and smears were prepared. Smears were wet fixed in $95 \%$ ethyl alcohol at least for 30 minutes and Papanicolaou (Pap) staining was done. Air dried smears were stained with May-Grunwald Giemsa (MGG) stain. Stained smears were mounted with DPX (dextrene polystyrene xylene) and examined under the light microscope.

\section{Results}

In the present study, 150 cases of SGLs (Salivary gland lesions) were studied in rural based population by using the Milan System of reporting cytology.

Manuscript received: $5^{\text {th }}$ February 2019

Reviewed: $13^{\text {th }}$ February 2019

Author Corrected: $18^{\text {th }}$ February 2019

Accepted for Publication: $22^{\text {nd }}$ February 2019 
Original Research Article

Out of 150 cases, maximum lesions i.e. $84(56 \%)$ were observed in submandibular salivary gland followed by 53 $(35.33 \%)$ and $09(06 \%)$ lesions in parotid and sublingual salivary glands respectively. 4 lesions $(2.67 \%)$ were observed in minor salivary glands.

Table-1: Frequency distribution pattern in SGLs:

\begin{tabular}{|c|c|c|c|c|c|c|}
\hline Category & \multicolumn{2}{|c|}{ Cyto-diagnosis: } & Male & Female & Total & $\%$ \\
\hline I & \multicolumn{2}{|c|}{ Non- Diagnostic. } & 11 & 05 & 16 & 10.67 \\
\hline II & \multicolumn{2}{|c|}{ Non- Neoplastic. } & 32 & 38 & 70 & 46.67 \\
\hline III & \multicolumn{2}{|c|}{ AUS. } & 05 & 04 & 09 & 06.00 \\
\hline \multirow{2}{*}{ IV } & \multirow[b]{2}{*}{ Neoplasm: } & A. Benign: & 18 & 17 & 35 & 23.33 \\
\hline & & B. SUMP: & 02 & 00 & 02 & 01.33 \\
\hline V & \multicolumn{2}{|c|}{ SM: } & 03 & 03 & 06 & 04.00 \\
\hline \multirow[t]{2}{*}{ VI } & \multicolumn{2}{|c|}{ Malignant: } & 08 & 04 & 12 & 08.00 \\
\hline & \multicolumn{2}{|c|}{ Total } & 79 & 71 & 150 & 100 \\
\hline
\end{tabular}

Out of 150 cases, maximum lesions i.e. $70(46 \%)$ were non-neoplastic followed by 37 (24.66\%) of neoplastic lesions \& $16(10.67 \%)$ cases were non-diagnostic.

Non-neoplastic lesions included inflammatory, metaplastic and reactive lesions like acute, chronic \& granulomatous sialadenitis, sialoadenosis \& reactive lymphadenitis. About $9(06 \%)$ cases of AUS [Atypia of undetermined significance] were observed which was within the frequency of Milan's system of classification i.e. $10 \%$. Out of 37 cases of neoplastic lesions, $35(23.33 \%)$ cases were of benign subcategory while $02(01.33 \%)$ cases were of SUMP [Salivary gland neoplasm of Uncertain Malignant Potential]. 6 (04\%) cases were observed in category of suspicious of malignancy [SM].

$12(08 \%)$ cases were observed as malignant lesions. In our study, the age group of the patients ranged from 02 to 90 years with the mean age of 39.7 years. 79 cases were males and 71 cases were females with M: F ratio of 1.11:1. Nonneoplastic lesions [Category II] were commonly seen in the age group of 21-30 years while neoplastic lesions [Category IV] were commonly seen in the age group of 20 - 60 years. Malignant lesions and lesions with suspicious of malignancy [Category V \&VI] were commonly seen in the age group of $50-70$ years.

Table-2: Cytopathological categories of salivary gland lesions.

\begin{tabular}{|l|c|c|c|c|}
\hline SGLs & M & F & Total & $\mathbf{\%}$ \\
\hline Non-diagnostic samples & 11 & 05 & 16 & 10.67 \\
\hline Sialoadenosis & 01 & 00 & 01 & 0.67 \\
\hline Acute sialadenitis & 10 & 06 & 16 & 10.67 \\
\hline Chronic sialadenitis & 05 & 03 & 08 & 05.34 \\
\hline Granulomatous sialadenitis & 01 & 00 & 01 & 1.67 \\
\hline Lymphadenitis [Acute, reactive, chronic, granulomatous] & 14 & 29 & 43 & 28.67 \\
\hline Non-mucinous cysts & 00 & 01 & 01 & 00.67 \\
\hline AUS. & 05 & 04 & 09 & 06.00 \\
\hline Pleomorphic adenoma & 17 & 15 & 32 & 21.34 \\
\hline Basal cell adenoma[BCA] & 01 & 02 & 03 & 02.00 \\
\hline SUMP & 02 & 00 & 02 & 01.33 \\
\hline Other suspicious for malignancies & 03 & 03 & 06 & 04.00 \\
\hline Mucoepidermoid carcinoma[MEC] & 02 & 00 & 02 & 01.33 \\
\hline Lymphomas & 04 & 02 & 06 & 04.00 \\
\hline Metastasis & 02 & 02 & 04 & 02.67 \\
\hline Total & $\mathbf{7 9}$ & $\mathbf{7 1}$ & $\mathbf{1 5 0}$ & $\mathbf{1 0 0 . 0 0}$ \\
\hline
\end{tabular}

Out of 150 cases, 16 cases (10.67\%) were non-diagnostic, 16 (10.67\%) cases were of acute sialadenitis, 08 (5.34\%) cases were of chronic sialadenitis, 43 cases $(28.67 \%)$ of lymphadenitis including acute, chronic, granulomatous and tuberculous lymphadenitis, 32 (21.34\%) cases were of PA, 3 (2\%) cases were of BCA, 2 (1.33\%) cases were of high grade MEC, 6 (04\%) cases each of suspicious or malignant lesions \& lymphoma respectively, $4(2.67 \%)$ cases of secondaries from epithelial malignancies \& $01(0.67 \%)$ case each of sialo-adenosis and non-mucinous cyst respectively. 


\section{Discussion}

Original Research Article

FNAC has been well established role in the diagnosis of SGLs \& it is a safe, cost-efficient, minimally invasive procedure that helps the clinicians in the formulation of further management [4,5]. However, at many times it becomes a tedious job to diagnose accurately, mainly due to the similar microscopic picture of normal salivary gland elements, heterogeneous nature of salivary gland lesions, overlapping features between benign and malignant lesions, presence of cystic components, and oncocytic metaplasia [6]. Aspirates from SGLs in category I were reported as non-diagnostic only after processing \& examining all the material. Cases with mucinous cyst contents were included in AUS category.

Table-3: Comparison of distribution of SGLs:

\begin{tabular}{|c|c|c|c|c|c|}
\hline \multirow{2}{*}{ 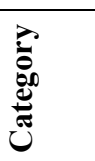 } & \multicolumn{5}{|c|}{ Studies } \\
\hline & $\begin{array}{c}\text { Jaiswal P } \\
\text { et al [7]. }\end{array}$ & $\begin{array}{c}\text { Viswanathan K et } \\
\text { al [8]. }\end{array}$ & $\begin{array}{l}\text { Savant D } \\
\text { et al [9]. }\end{array}$ & $\begin{array}{c}\text { Montezuma D et al } \\
{[10] .}\end{array}$ & Present study \\
\hline I & $3(4.91 \%)$ & $75(12 \%)$ & $18(9.2 \%)$ & $28(7.21 \%)$ & $16(10.67 \%)$ \\
\hline II & $15(24.59 \%)$ & $179(28.5 \%)$ & $4(2 \%)$ & $89(22.93 \%)$ & $70(46.67 \%)$ \\
\hline III & $1(1.64 \%)$ & $38(6.1 \%)$ & $12(6 \%)$ & $39(10.05 \%)$ & $9(6 \%)$ \\
\hline IV-A & $28(45.90 \%)$ & $197(31.4 \%)$ & $118(59.2 \%)$ & $156(40.21 \%)$ & $35(23.33 \%)$ \\
\hline IV-B & $1(1.64 \%)$ & $62(9.9 \%)$ & $22(11 \%)$ & $55(14.18 \%)$ & $2(1.33 \%)$ \\
\hline $\mathrm{V}$ & $1(1.64 \%)$ & $17(2.7 \%)$ & $3(1.5 \%)$ & $7(1.80 \%)$ & $6(4 \%)$ \\
\hline VI & $13(21.31 \%)$ & $59(9.4 \%)$ & $22(11 \%)$ & $14(3.60 \%)$ & $12(8 \%)$ \\
\hline Total & $61(100 \%)$ & $627(100 \%)$ & $199(100 \%)$ & $388(100 \%)$ & $150(100 \%)$ \\
\hline
\end{tabular}

In the present study, non-diagnosticcases [I] were $16(10.67 \%)$ which is comparable with the study done by Viswanathan $\mathrm{K}$ et al [8] \& Savant D et al [9].

This comprised of smears with less than 60 lesional cells, poorly prepared slides with artifacts [Fig:1A], slides with normal salivary gland elements in unilateral swellings, non-mucinous cyst contents showing cyst fluid only or histiocytes [Fig. 1B].

Aspirates lacking clear cytomorphologic evidences of neoplastic process were reported as category II: non-neoplastic. In our study, non-neoplastic SGLs included were acute sialadenitis [Fig:1 C], chronic sialadenitis [Fig:1D], granulomatous/ tuberculous sialadenitis [Fig: 2A, B, C], sialoadenosis, sialolithiasis and reactive lymph node hyperplasia's. Being this study done in rural population, it seems that non-neoplastic lesions i.e. 70(46.67\%) were observed more as compared to other studies. Mucinous cyst lesions [Fig: 2D], reactive atypia [Fig: 3A] observed in the smears were included in AUS / category III which was comparable i.e.09 (06\%) to the studies done by Viswanathan K et al [8] \& Savant D et al [9].

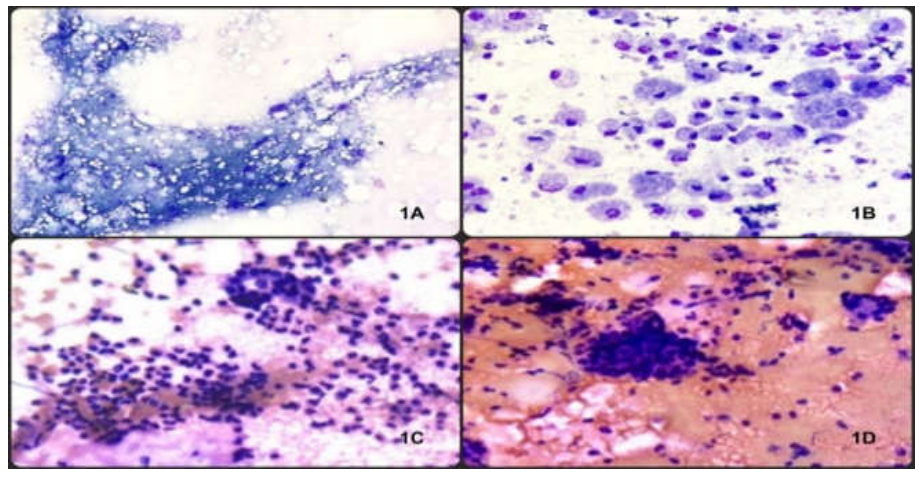

Fig. 1A: Nondiagnostic [I]: Inadequate smear: shows less than 60 cells in the background of hemorrhage [MGG: $5 \mathrm{X}]$

Fig.1B: Nondiagnostic [I]: Non-mucinous cyst: shows plenty of cyst macrophages [MGG: 40X].

Fig.1C: Non-neoplastic [II]: Acute sialadenitis: shows occasional epithelial cells admixed with plenty of polymorphs. [PAP: 10X]

Fig.1D: Non-neoplastic [II]: Chronic sialadenitis: shows acinar cells \& lymphocytes in the hemorrhagic background. [PAP: 10X] 


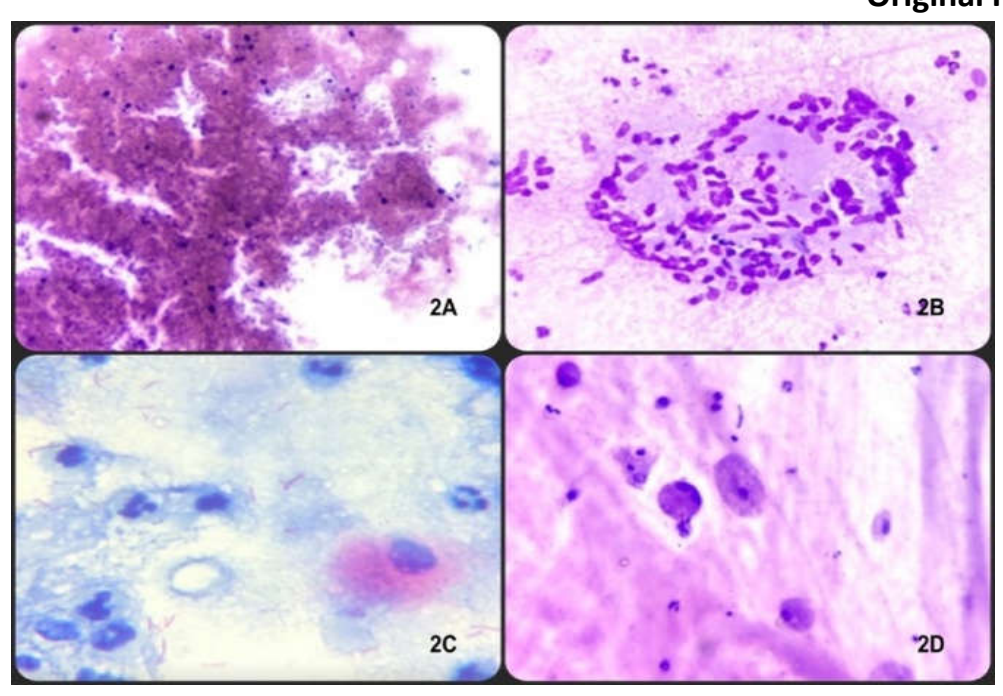

Fig.2A: Non-Neoplastic [II]: Tuberculous lymphadenitis: shows few inflammatory cells admixed with abundant caseous necrosis. [PAP: 10X]

Fig.2B: Non-neoplastic [II]: Tuberculous lymphadenitis: shows epitheloid cells \& foreign body giant cells. [MGG: 40X]

Fig.2C: Non-neoplastic [II]: Tuberculous lymphadenitis: shows acid fast bacilli. [ZN stain: 40X]

Fig.2D: AUS [III]: Mucinous cyst: shows cyst macrophages (mucinophages) in the background of abundant mucin. [MGG: 40X].

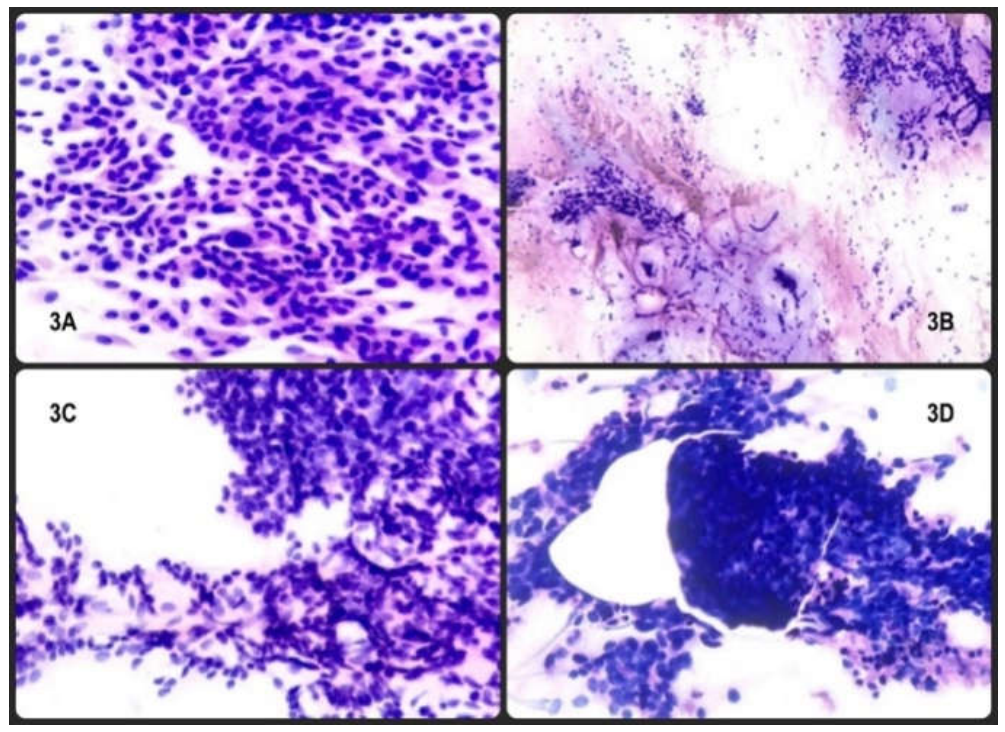

Fig.3A: AUS [III]: shows epithelial cells admixed with occasional atypical cells with large hyperchromatic nuclei. [PAP: 40X]

Fig. B: Neoplasm [IV: A]: PA shows epithelial cells \& mesenchymal spindle cells in the chondromyxoid ground substance. [PAP: 10X]

Fig.3C: Neoplasm [IV: A]: Basal cell adenoma (Trabecular variant): shows multiple hyaline stromal globules surrounded by bland epithelial or basal cells. [PAP: 40X]

Fig.3D: Neoplasm [IV: B]: SUMP: Highly cellular PA with atypia: shows highly cellular, matrix poor pleomorphic adenoma with atypia. [PAP: 40X]

The benign neoplasms with no definite evidence of malignancywere reported in category IV i.e. Neoplastic: A- Benign. 35 (23.33\%) cases including PA [Fig: 3B] and BCA [Fig: 3C] were observed in this study which was comparable to study done by Viswanathan K et al [8]. 


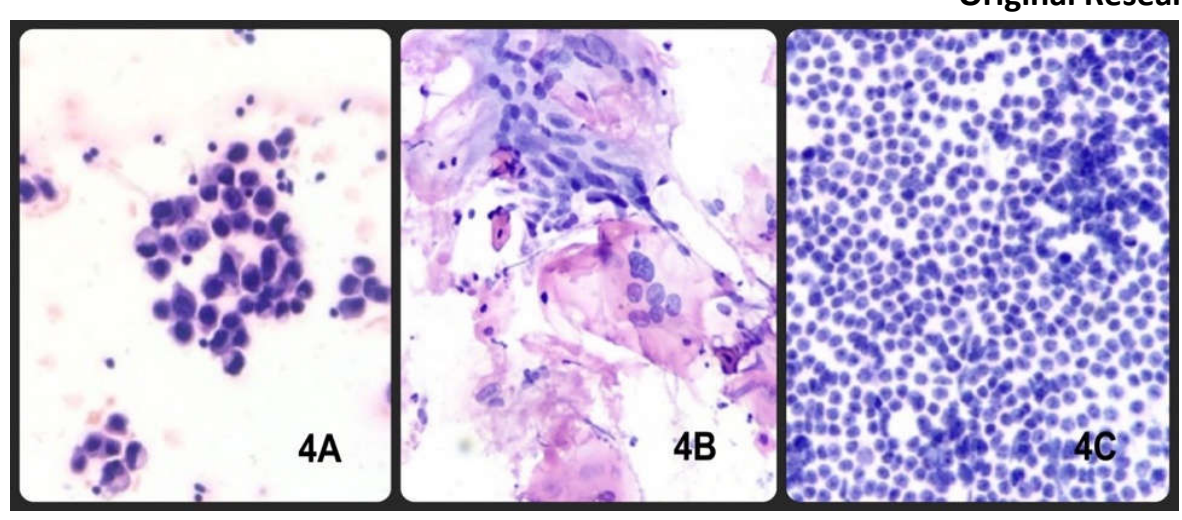

Fig.4A: Suspicious for malignancy [V]: shows groups of markedly atypical cells with hyperchromatic nuclei. [PAP: 40X]

Fig. 4B: Malignant [VI]: SCC: shows malignant squamous cells admixed with foreign body giant cells. [PAP: 40X]

Fig. 4C: Malignant [VI]: NHL: shows monomorphic population of lymphoid cells [PAP: 40X]

In the category IV/ Neoplastic: B: SUMP, two cases i.e. 2(1.33\%) [Fig: 3D] with high cellularity and or atypia with suspicious of malignant potential were included which was comparable to previous study done by Jaiswal P et al [7].

$6(04 \%)$ cases [Fig: 4A] of SM were observed in our present study which showed markedly atypical cells.12 (08\%) cases of malignant SGLs were observed in our study which included MEC, SCC [Fig: 4B], NHL[Fig:4C] and metastasis, which was comparable to study done by Viswanathan K et al [8].

\section{Table-4: Comparison of age wise distribution pattern in SGL:}

Present study showed maximum cases in age group of 31-40 years with a mean age of 39.7 years, which was comparable to studies done by Kakoty S et al [11] \& Shafkat A et al [13].

\begin{tabular}{|c|c|c|c|c|c|c|c|c|}
\hline \multirow{2}{*}{$\begin{array}{c}\text { Age Group } \\
\text { (Years) }\end{array}$} & \multicolumn{9}{|c|}{ Studies } \\
\cline { 2 - 9 } & $\begin{array}{c}\text { Kakoty S. } \\
\text { et al [11]. }\end{array}$ & \multicolumn{2}{c|}{$\begin{array}{c}\text { Dalve K. } \\
\text { et al [12]. }\end{array}$} & \multicolumn{2}{c|}{$\begin{array}{c}\text { Shafkat A. } \\
\text { et al [13]. }\end{array}$} & \multicolumn{2}{c|}{$\begin{array}{c}\text { Present } \\
\text { study }\end{array}$} \\
\cline { 2 - 9 } & Cases & $\mathbf{\%}$ & Cases & $\mathbf{\%}$ & Cases & $\mathbf{\%}$ & Cases & \% \\
\hline $0-10$ & 00 & 00 & 01 & 01.08 & 05 & 05 & 12 & 08.00 \\
\hline $11-20$ & 07 & 14 & 13 & 14.13 & 12 & 12 & 19 & 12.67 \\
\hline $21-30$ & 10 & 20 & 14 & 15.21 & 22 & 22 & 25 & 16.67 \\
\hline $31-40$ & 15 & 30 & 11 & 11.96 & 26 & 26 & 26 & 17.33 \\
\hline $41-50$ & 10 & 20 & 18 & 19.57 & 18 & 18 & 23 & 15.33 \\
\hline $51-60$ & 06 & 12 & 11 & 11.96 & 12 & 12 & 17 & 11.33 \\
\hline $61-70$ & 02 & 04 & 19 & 20.65 & 04 & 04 & 22 & 14.67 \\
\hline $71-80$ & 00 & 00 & 04 & 04.36 & 01 & 01 & 04 & 02.67 \\
\hline $81-90$ & 00 & 00 & 01 & 01.08 & 00 & 00 & 02 & 01.33 \\
\hline Total & $\mathbf{5 0}$ & $\mathbf{1 0 0}$ & $\mathbf{9 2}$ & $\mathbf{1 0 0}$ & $\mathbf{1 0 0}$ & $\mathbf{1 0 0}$ & $\mathbf{1 5 0}$ & $\mathbf{1 0 0}$ \\
\hline
\end{tabular}

Table 5: Comparison of sex wise distribution pattern in SGLs:

\begin{tabular}{|c|c|c|c|}
\hline Studies & M & F & M:F \\
\hline Jain C. $^{14}$ & $42(52.5 \%)$ & $38(47.5 \%)$ & $1.10: 1$ \\
\hline Gandhi SH et al. $^{15}$ & $53(58.8 \%)$ & $37(41.1 \%)$ & $2.43: 1$ \\
\hline Singh Nanda et al. $^{16}$ & $90(70.8 \%)$ & $37(29.1 \%)$ & $1.11: 1$ \\
\hline Present study & $79(53 \%)$ & $71(47 \%)$ & 1 \\
\hline
\end{tabular}

In the present study of 150 salivary gland lesions, male preponderance was observed with male to female ratio of 1.1: 1, which was comparable to studies done by Jain C [14] and Gandhi SH. et al [15]. 
Table-6: Comparison of site wise distribution pattern in SGLs:

Original Research Article

\begin{tabular}{|c|c|c|c|c|c|}
\hline Studies/ Sites & Parotid & Submandibular & Sublingual & Minor & Total \\
\hline Jain C [14] & $38(54.28 \%)$ & $31(44.28 \%)$ & & $1(1.42 \%)$ & 70 \\
\hline Singh Net al [16] & $65(51.1 \%)$ & $47(37 \%)$ & $6(4.7 \%)$ & $9(7 \%)$ & 127 \\
\hline Singh Aet al [17] & $76(79.16 \%)$ & $18(18.75 \%)$ & & $2(2.8 \%)$ & 96 \\
\hline Ashraf Aet al [18] & $68(68 \%)$ & $30(30 \%)$ & & $2(2 \%)$ & 100 \\
\hline Vaidya Set al [19] & $27(46.5 \%)$ & $27(46.5 \%)$ & $1(1.7 \%)$ & $3(5.2 \%)$ & 58 \\
\hline Present study & $53(35.33 \%)$ & $83(56 \%)$ & $9(6 \%)$ & $4(2.67 \%)$ & 150 \\
\hline
\end{tabular}

In the present study of 150 cases of SGL's, submandibular gland was most commonly affected i.e. in 83 (56\%) cases followed by parotid gland $53(35.33 \%)$ cases and sublingual salivary gland $9(6 \%)$ cases. Minor salivary glands were affected in 4 (2.67\%) cases which was comparable to study done by Singh A et al [17] \& Ashraf A et al [18].

Benign tumors were more common in the age group of 21- 60 year and malignant tumors were more common in the age group of 61-80 years which was comparable to the study done by Joshi A et al [20].

\section{Conclusion}

150 cases of SGLs were studied in rural based population by using the Milan system of reporting cytopathology. Submandibular salivary gland was most commonly affected followed by parotid gland, minor salivary glands and sublingual gland respectively. Age range in our study was from 2- 90 years with mean age 39.7 years. Male preponderance was observed with M: F of 1.11: 1. Non-neoplastic lesions were more common than neoplastic SGL's. Benign tumors were more common in the age group 21-40 years while malignant tumors were more common in the age group of 6180 years. PA was the most common benign tumor and MEC was the most common primary malignant tumor.

Role of FNAC, its diagnostic utility in the rural based population combined with the use of Milan System of reporting cytopathology in SGLs was found characteristically significant for cytological diagnosis.

Both the authors had equally contributed regarding concept, design, literature search, data analysis and preparation of this manuscript. No prior publication, support and conflict of interest.

Findings: Nil; Conflict of Interest: None initiated Permission from IRB: Yes

\section{References}

1. Akhter J, Hirachand S, Lakhey M. Role of FNAC in the diagnosis of salivary gland swellings. Kathmandu Univ Med J (KUMJ). 2008 Apr-Jun;6(2):204-8.

2. Ameli F, Baharoom A, Md Isa N, et al. Diagnostic challenges in fine needle aspiration cytology of salivary gland lesions. Malays J Pathol. 2015 Apr;37(1):11-8.
3. Manvi G, Varun G, Preeti B. Role of preoperative cytology in the management of salivarygland lesions. $\mathrm{J}$ Evol Med Dent Sci. 2013:7475- 82.

4. Wong DS, Li GK. The role of fine-needle aspiration cytology in the management of parotid tumors: a critical clinical appraisal. Head Neck. 2000 Aug; 22 (5): 469-73.

5. Mairembam P, Jay A, Beale T, et al. Salivary gland FNA cytology: role as a triage tool and an approach to pitfalls in cytomorphology. Cytopathology. 2016 Apr;27 (2): 91-6. doi: 10.1111/cyt. 12232. Epub 2015 Feb 6.

6. Tyagi R, Dey P. Diagnostic problems of salivary gland tumors. Diagn Cytopathol. 2015 Jun; 43 (6): 495 509. doi: 10. 1002/dc. 23255. Epub 2015 Jan 22.

7. Jaiswal P, Sharma M, Ahmad F, Khan NS, Sinha SS. Riskbased stratification of salivary gland lesions on cytology: An institutional experience. Iran $\mathrm{J}$ Pathol 2018; 13 (2): 220- 28.

8. Viswanathan K, Sung S, Scognamiglio T, Yang $\mathrm{GCH}$. The role of the Milan system for reporting salivary gland cytopathology: A 5 year institutional experience. Cancer cytopatology. Published: March 2018; Wiley Online Library: 1- 11.

9. Savant D, Jin C, Chau K, et al. Risk stratification of salivary gland cytology utilizing the Milan system of classification. Diagn Cytopathol. 2019 Mar;47(3):172180. doi: 10.1002/dc.24063. Epub 2018 Nov 26. 
10. Montezuma D, Canberk S, Aydin O, Dermirhas MP, Vieira AF, Goksel S, et al. Comparision of the reporting system of salivary gland fine needle aspirations: Are they really different? Diagn Cytopathol 2018; 46 (10): 859- 63.

11. Kakoty S, Baruah TD, Babu CPG. FNAC and histopathological correlation of salivary gland lesions : an observational study. Int Surg J 2017; 4: 2148- 52.

12. Dalve KT, Swami SY, Rutuja LU, Narhire V V, Bakshi AP. Study of FNAC of salivary gland lesions in a tertiary care hospital. J Diagnostic Pathol Oncol 2016; 1 (2): 24- 28.

13. Shafakat Ahmad, Mohainmad Lateef, Rouf Ahemad. Clinicopathological study of primary salivarygland tumours in kashmir.JK-practioner 2002; 9 [4]: 231- 33 .

14. Jain C. Fine needle aspiration cytology of salivary gland lesions: a study of 70 cases. Int J Med Pharm Sci 2013; 3 (7): 1 - 10.

15.GandhiSH,PurohitTM,Purohit MB, JethwaniD,Vidja M.FNAC diagnosis of salivary gland lesions with histopathological correlation. NJIRM 2013; 4(3): 70- 77.
16. Singh Nanda KD, Mehta A, Nanda J. Fine-needle aspiration cytology: a reliable tool in the diagnosis of salivary gland lesions. J Oral Pathol Med. 2012 Jan; 41 (1): 106-12. doi: 10.1111/j.1600-0714.2011. 01069.x. Epub 2011 Aug 29.

17. Singh A, Haritwal A, Murali BM. Correlation between cytology and histopathology of the salivary gland. Australas Med J 2011; 4 (2): 66- 71.

18. Ashraf A, Shaikh AS, Kamal F, et al. Diagnostic reliability of FNAC for salivary gland swellings: a comparative study. Diagn Cytopathol. 2010 Jul;38(7): 499-504. doi: 10.1002/dc.21211.

19. Vaidya S, Sinha A, Narayan S, Adhikari S, Sabira KC. A comparative study of fine-needle aspiration cytology and histopathology in salivary gland lesions. J Pathol Nepal 2011; 1: 108- 13.

20. Joshi AR, Jadhav DS, Baste BD, Ranka SK. A study of fine needle aspiration cytology in salivary gland lesions in a rural population. Int J Adv Med 2017; 4 (2): $307-10$.

\section{How to cite this article?}

Mahammadtalha B, Swami S.Y. Cytopathological study of salivary gland lesions in rural population: Use of the Milan system for reporting. Trop J Path Micro 2019;5(2):100-106.doi:10.17511/jopm.2019.i02.09. 